\title{
Disintegration Rate
}

National Cancer Institute

\section{Source}

National Cancer Institute. Disintegration Rate. NCI Thesaurus. Code C94886.

The number of radioactive transformations per unit time and expressed as

disinteg rations per minute or disintegrations per second. It is the unit of measure for quantities of radionuclide. 